\title{
Evaluation of Radar Reflectivity-Based Estimates of Water Content in Stratiform Marine Clouds
}

\author{
SERGEy Y. MAtrosov \\ Cooperative Institute for Research in the Environmental Sciences, University of Colorado, and \\ NOAA/Environmental Technology Laboratory, Boulder, Colorado \\ Taneil Uttal and Duane A. Hazen \\ NOAA/Environmental Technology Laboratory, Boulder, Colorado
}

(Manuscript received 13 July 2003, in final form 10 September 2003)

ABSTRACT

\begin{abstract}
The performance of radar reflectivity $\left(Z_{e}\right)$-based relations for retrievals of marine stratiform cloud liquid water content (LWC) is evaluated by comparing liquid water path (LWP) estimates from microwave radiometers with vertically integrated LWC values retrieved from radar measurements. Based on a measurement dataset from a research vessel in the tropical eastern Pacific Ocean, it is shown that reflectivity thresholding allows minimizing of the influence of drizzle drops present in marine stratiform clouds to the extent that LWP estimates from a ground-/shipborne radar can have uncertainties that might be acceptable for different applications. The accuracies of $Z_{e}$-based retrievals depend on the thresholding level $Z_{\mathrm{et}}$, and they are generally better than a factor of 2 for $Z_{\mathrm{et}} \lessgtr-15 \mathrm{dBZ}$. These accuracies typically improve when $Z_{\mathrm{et}}$ is lowered; however, the amount of cloud profiles that pass thresholding diminishes as $Z_{\mathrm{et}}$ is decreased from about $50 \%$ for a -15 -dbZ threshold to only about $10 \%$ for a $-25-\mathrm{dBZ}$ threshold. Different thresholding strategies are considered. Ancillary information on cloudbase heights can improve LWP estimates from reflectivities. The ship-based dataset was used to simulate measurements from prospective 94-GHz spaceborne cloud radar (CloudSat). CloudSat measurements would, on average, detect about $75 \%$ of warm marine stratiform clouds, though many clouds with negligible presence of drizzle will be missed. Because of sensitivity and resolution issues for the spaceborne radar, reflectivity-based estimates of LWP are generally biased toward high values and have higher uncertainties when compared with the ground-based radar, for the same $Z_{\mathrm{et}}$.
\end{abstract}

\section{Introduction}

Layers of marine stratiform (e.g., stratus and stratocumulus) clouds occur over large areas, especially in the eastern parts of the oceans with generally cooler water surface temperatures. Because of their extensive and persistent nature, these clouds play an important role in the global radiative budget modulating the shortwave radiation balance because of their high albedo relative to the underlying ocean. Their effect on the longwave radiation is often less significant, because of relatively small temperature differences between the surface and cloud tops. These clouds are composed of liquid water drops, and their radiative properties are determined by the macrophysical characteristics (e.g., cloud thickness) and by the microphysical parameters, such as the effective drop radius $\left(r_{e}\right)$ and liquid water content (LWC). The potentially large impact of stratiform clouds on climate and their importance in bound-

Corresponding author address: Dr. Sergey Y. Matrosov, R/ET7, 325 Broadway, Boulder, CO 80303.

E-mail: sergey.matrosov@noaa.gov ary layer dynamics require observational data on the microphysical properties of these clouds.

A number of passive remote sensing techniques have been developed for retrieving the microphysical parameters of liquid water stratiform clouds. Satellite techniques often use combinations of visible and/or infrared radiance measurements to infer cloud microphysical properties (e.g., Lin and Rossow 1994; Han et al. 1994; Young et al. 1997; Minnis et al. 1998). The retrieved information, however, is weighted toward cloud tops because the liquid water clouds are usually optically opaque within a few tens of meters from their tops. These approaches also have difficulties with multilayer cloud scenes, especially ones with upper-level ice clouds. Spaceborne multichannel microwave radiometers (MWR) offer estimates of cloud liquid water path (LWP), providing valuable climatological information (Zuidema and Hartmann 1995), though the sensitivity and resolution issues often limit their capabilities for sensing relatively thin and broken stratus clouds (Greenwald et al. 1995). An important limitation of passive measurements is that they do not reveal the vertical structure of clouds. 
Active remote sensors (e.g., lidars and radars) have an advantage over passive sensors in their ability to provide vertically resolved information on clouds, although the use of lidars for remote sensing of liquid clouds is limited because of the quick extinction of lidar signals in liquid phase. Millimeter-wavelength radar, however, has proved to be a very valuable tool in cloud studies. Cloud radars usually operate in one of the frequency "windows" centered either at around 35 (Ka band) or 90 (W band) GHz. Several ground-based methods that use cloud radars in combination with information from different passive instruments have been proposed for retrieving microphysical properties of warm stratiform clouds (e.g., Frisch et al. 1995; Sassen et al. 1999; Mace and Sassen 2000; Loehnert et al. 2001; Dong and Mace 2003).

Although multisensor retrieval approaches are generally more robust than single-sensor approaches, a need still exists for radar-only retrievals of liquid cloud parameters when supporting radiometric measurements are unavailable or unusable. Radar-only retrievals will be important for use with the W-band satelliteborne cloud radar (CloudSat; Stephens et al. 2002). CloudSat will be a part of a satellite constellation flying in close coordination. This constellation is referred to as the Atrain and consists of four more satellites besides CloudSat (Stephens et al. 2002). Although other satellites in the A-train will carry a wealth of different sensors, cloud retrieval algorithms that use only radar reflectivity need to be developed for special uses (e.g., nighttime spaceborne radar retrievals).

One important problem for radar-only retrievals in stratiform liquid clouds is caused by drizzle-size drops. Almost all marine (Fox and Illingworth 1997) and some continental stratiform liquid water clouds contain a certain amount of drizzle drops that are usually defined as drops with 100-250- $\mu \mathrm{m}$ radii. Because the occasional drizzle drops affect the radar moments [which are proportional to the sixth moment of the drop size distribution (DSD)] more strongly than LWC (which is proportional to the third moment of the DSD), it is generally expected that the radar reflectivity-based algorithms will produce biased results when applied to marine clouds. The drizzle component of the total reflectivity potentially can be estimated if the Doppler radar spectrum at vertical incidence is available. This is, however, not an option for the CloudSat radar because it will not have Doppler capability and it is often problematic for Doppler radars deployed on movable platforms, such as ships. This study suggests an approach that uses reflectivity thresholding to determine conditions for meaningful applications of radar-reflectivity-only-based retrievals of liquid water content. It provides assessments of uncertainties and biases of such retrievals caused by drizzle.

\section{Reflectivity-based estimators}

Cloud DSDs are usually modeled by three-parameter functions, such as lognormal functions or gamma func- tions of different orders $n$. Though shapes of these functions are quite similar for $n \geq 2$, the lognormal functions are used more often for describing drop spectra because they allow for easy integrations of the distribution moments (e.g., Matveev 1976). These functions are given in terms of drop radius $r$ and depend on total drop concentration $N_{o}$, mean logarithmic drop radius $\ln \left(r_{o}\right)$, and the distribution width $\sigma$, which is dimensionless:

$$
\begin{aligned}
N(r)= & N_{o}(2 \pi)^{-0.5}(\sigma r)^{-1} \\
& \times \exp \left\{-0.5\left[\ln (r)-\ln \left(r_{o}\right)\right] \sigma^{-2}\right\} .
\end{aligned}
$$

The effective drop radius $r_{e}$, defined as the ratio of the third and second moments of the DSD, relates to $r_{o}$ as $r_{e}=r_{o} \exp \left(2.5 \sigma^{2}\right)$. By calculating different moments of (1), one can get expressions for the radar reflectivity factor $Z_{e}$, visible extinction coefficient $\alpha$, and cloud LWC:

$$
\begin{aligned}
Z_{e} & =2^{6} N_{o} r_{e}^{6} \exp \left(3 \sigma^{2}\right), \\
\alpha & =2 \pi N_{o} r_{e}^{2} \exp \left(-3 \sigma^{2}\right), \quad \text { and } \\
\mathrm{LWC} & =(4 / 3) \pi \rho N_{o} r_{e}^{3} \exp \left(-3 \sigma^{2}\right),
\end{aligned}
$$

where $\rho$ is the density of water. When deriving (2)-(4), it was assumed that $r \ll \lambda$ (i.e., the Rayleigh-scattering regime at the radar wavelength $\lambda$ ) and that the drop extinction efficiency is 2 (i.e., the large-particle approximation at visible wavelengths).

From (2) and (4), one can get expressions for $r_{e}$ and LWC as functions of $Z_{e}$ as presented by Matrosov (2000):

$$
r_{e}=\left[2 \exp \left(0.5 \sigma^{2}\right) N_{o}^{1 / 6}\right]^{-1} Z_{e}^{1 / 6}=a_{2}\left(N_{o}, \sigma\right) Z_{e}^{1 / 6}
$$

and

$$
\begin{aligned}
\mathrm{LWC} & =(\pi / 6) \rho N_{o}^{0.5} \exp \left(-4.5 \sigma^{2}\right) Z_{e}^{1 / 2} \\
& =a_{1}\left(N_{o}, \sigma\right) Z_{e}^{1 / 2} .
\end{aligned}
$$

Equation (5) is essentially equivalent to the $r_{e}-Z_{e}$ relations considered by Frisch et al. (2002) and Dong and Mace (2003). Making appropriate assumptions about $N_{o}$ and $\sigma$ results in $r_{e}-Z_{e}$ and $\mathrm{LWC}-Z_{e}$ relations for the liquid water clouds. Fixing $N_{o}$ and $\sigma$ in (1) implies a direct relation between $\mathrm{LWC}$ and $r_{e}$ for a given $Z_{e}$, allowing calculations of two parameters (i.e., LWC and $r_{e}$ ) from one measurement of $Z_{e}$.

Miles et al. (2000) recently summarized available in situ data on stratiform-cloud drop size distributions. They categorized their findings into two major types: continental and marine clouds. A mean value of the distribution logarithmic width was approximately the same for both cloud types- $\sigma \approx 0.38$-although some datasets had large values of $\sigma$, which may have been caused by drizzle contributions. The mean drop concentration was about $75 \mathrm{~cm}^{-3}$ for marine clouds and about $280 \mathrm{~cm}^{-3}$ for continental clouds. This difference is mostly associated with a significantly lower amount of cloud condensation nuclei (CCN) over oceans as 
compared with landmasses. Based on these empirical data, mean coefficients in (5) and (6) are $a_{1}\left(N_{o}, \sigma\right) \approx$ $2.4, a_{2}\left(N_{o}, \sigma\right) \approx 22.7$ for marine clouds and $a_{1}\left(N_{o}, \sigma\right)$ $\approx 4.6, a_{2}\left(N_{o}, \sigma\right) \approx 18.1$ for continental clouds $\left[Z_{e}\left(\mathrm{~mm}^{6}\right.\right.$ $\left.\left.\mathrm{m}^{-3}\right), r_{e}(\mu \mathrm{m}), \mathrm{LWC}\left(\mathrm{g} \mathrm{m}^{-3}\right)\right]$. Note that the $\mathrm{LWC}-Z_{e}$ relation for continental clouds is in relatively close agreement with earlier relations proposed by Atlas (1954) $\left(\mathrm{LWC}=4.5 Z_{e}^{0.5}\right)$ and Sauvageot and Omar $(1987)\left(\mathrm{LWC}=5.3 Z_{e}^{0.54}\right)$.

The exponents in (5) and (6) (i.e., 1/6 and 0.5) are assumed to be constant, and they do not depend on $N_{o}$ and $\sigma$. The analysis of in situ data given by Miles et al. (2000) also shows that $N_{o}$ and $\sigma$ for marine clouds and $\sigma$ for continental clouds do not exhibit significant trends with height within the cloud, though there is a slight trend for $N_{o}$ to increase with height for continental clouds. This indicates that the coefficients $a_{1}$ and $a_{2}$ are nearly constant with height for marine clouds, and that they could somewhat increase $\left(a_{1}\right)$ and decrease $\left(a_{2}\right)$ with height within the cloud for continental clouds. Additional arguments for the assumption of $N_{o}$ and $\sigma$ being constant with height, even for continental clouds, are discussed by Frisch et al. (2002).

If the additional measurements (besides $Z_{e}$ ) are available, one of the quantities (either $N_{o}$ or $\sigma$ ) can be determined. Some techniques use collocated radiometric measurements to get an estimate of $N_{o}$ (e.g., Frisch et al. 1995). Austin and Stephens (2001) describe an algorithm of deriving stratiform cloud properties from measurements of $Z_{e}$ and the cloud optical thickness $\tau$ (i.e., the vertical integral of $\alpha$ ) based on statistical regularization formalism. This algorithm is intended for daytime use with the CloudSat radar $Z_{e}$ measurements and closely collocated estimates of $\tau$ from other A-train satellites. The interest of this study, however, is to evaluate uncertainties and limitations of reflectivity-cloud parameter relations that can be applied when no additional measurements are available. We concentrate on $\mathrm{LWC}-Z_{e}$ relations because they can be validated using independent estimates of liquid water path from microwave radiometers. Of main concern are the warm marine stratiform clouds because of their importance to climate studies and retrieval difficulties caused by the presence of drizzle.

The addition of drizzle-sized drops to cloud leads to a much stronger increase in $Z_{e}$ than in LWC because of the proportionality to different moments of $\operatorname{DSD}\left(Z_{e} \propto\right.$ $D^{6}$, LWC $\left.\propto D^{3}\right)$. As a result, relation (6), which is originally tuned for cloud phase, breaks down because values of $\sigma$ and, especially, $N_{o}$ (drizzle drops are characterized by much smaller concentrations than cloud drops) that are used to calculate the coefficient $a_{1}\left(N_{o}\right.$, $\sigma)$ are not representative of drizzle. These values from Miles et al. (2000) characterize cloud phase and fail to provide sizes of drizzle drops, as can be seen from (5). Because the addition of drizzle to cloud phase mainly results in an increase of reflectivity (a corresponding increase in LWC is generally small), one could expect

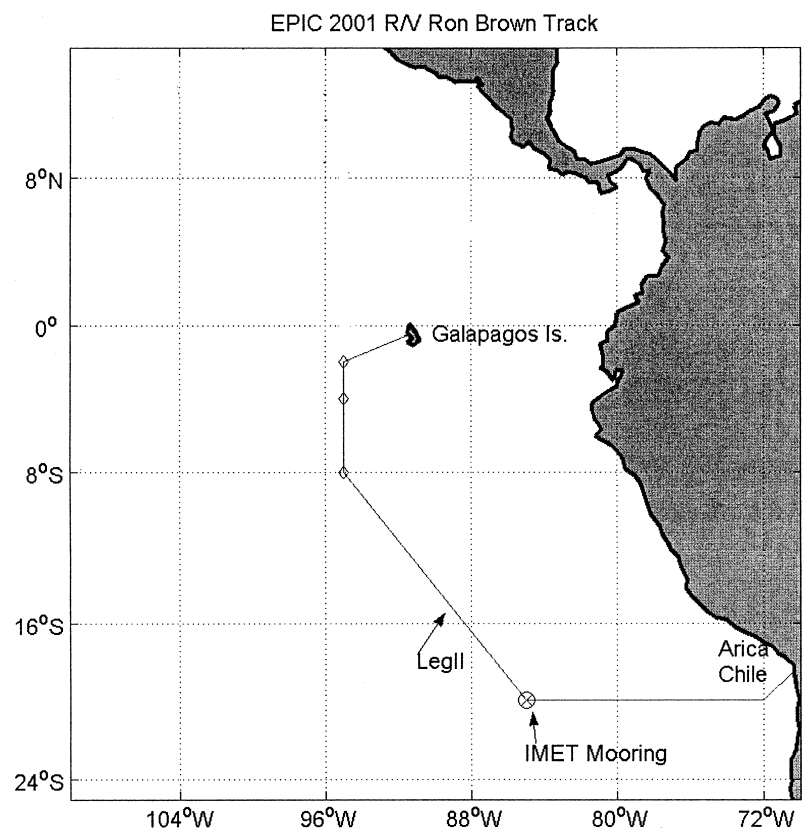

FIG. 1. The map of the second leg of the EPIC 2001 cruise.

that a deteriorating performance of cloud $Z_{e}-$ LWC estimators as a progressively greater fraction of the observed reflectivity is due to drizzle-sized drops. This study assesses the gradual deterioration of cloud content estimates from reflectivity as a function of the reflectivity thresholding level.

\section{Experimental dataset}

The dataset for the radar-based retrievals of marine stratiform clouds was obtained during the East Pacific Investigation of Climate (EPIC) field experiment (Bretherton et al. 2004). This experiment was conducted in the autumn of 2001 in the tropical east Pacific. A suite of instruments was deployed on the National Oceanic and Atmospheric Administration (NOAA) research vessel Ronald H. Brown, including a cloud-base lidar ceilometer, the Environmental Technology Laboratory (ETL) vertically pointing 8-mm (35 GHz) wavelength cloud radar (MMCR), and a two-channel (20.6, 31.65 $\mathrm{GHz}$ ) microwave radiometer. The second leg of the EPIC experiment (10-24 October) took place south of the Galapagos Islands in the marine area that is known for persistent low-level stratocumulus clouds. The research vessel tracks are shown in Fig. 1.

Stratocumulus clouds were observed during all 15 days of the second leg. The daily cross sections of the MMCR reflectivities $Z_{e}$ are shown in Fig. 2. The sensitivity of this radar allows detection of virtually all marine atmospheric boundary layer clouds. The dynamic range of observed reflectivities is about six orders of magnitude. The average cloud fraction for the whole period was $92 \%$. The individual cloud fractions, which 

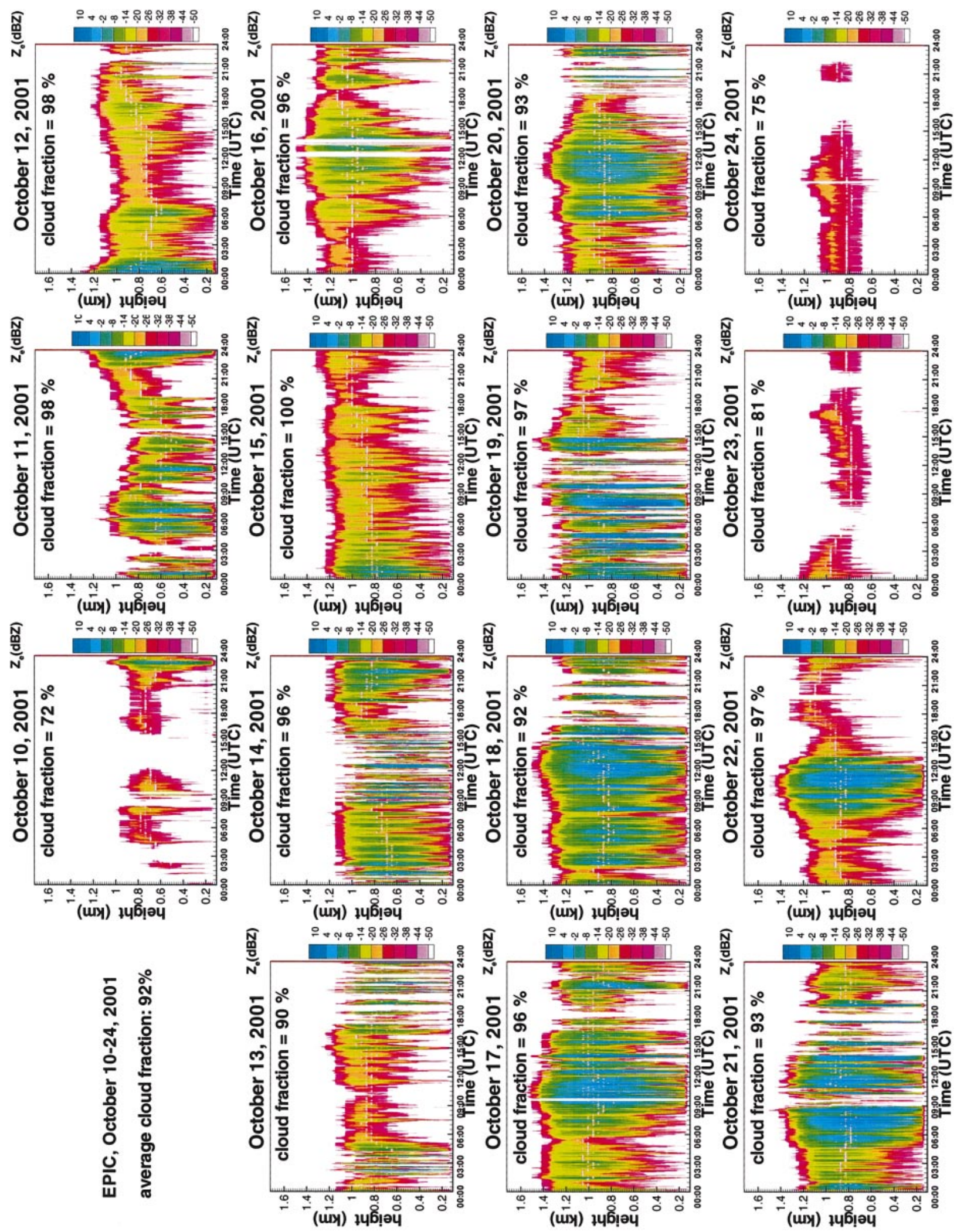
varied from $72 \%$ (10 October) to $100 \%$ (15 October), are also shown in each frame of Fig. 2. Maximum cloudtop heights were observed at about $1.5 \mathrm{~km}$, and the thickness of the radar echo layer varied from about a few hundred meters to more than $1 \mathrm{~km}$.

Presence of drizzle was rather persistent during the experiment. A diurnal cycle of heavier drizzle can be seen as areas of increased reflectivity (especially during 17-22 October), with most heavy drizzle events occurring during local nighttime and early morning hours. Most often, areas with the largest $Z_{e}$ values are observed at some height above the sea level, indicating evaporation processes as drizzle drops fall, although sometimes these drops reach the lowest observed level of $105 \mathrm{~m}$ (e.g., 19 October).

A crucial question for non-Doppler radar retrievals of warm stratiform clouds is how, using $Z_{e}$-only data, to distinguish between clouds where contributions of drizzle can be neglected and those where these contributions cause unacceptable errors. Though the MMCR has Doppler capability, it did not record Doppler spectra during EPIC 2001. One possible approach (Fox and Illingworth 1997; Mace and Sassen 2000) is to analyze the vertical profile of reflectivity. If the profile is characterized by small values of $Z_{e}$ and it shows a steady increase with altitude (mostly due to quasi-adiabatic processes in cloud), then the cloud can be considered drizzle free. Examples of this type of reflectivity profiles can be seen in clouds observed on 23-24 October. There is a gradual increase of $Z_{e}$ with height for these clouds, except in the vicinity of the cloud tops where quick evaporation takes place. This approach, however, will be of very limited use for the CloudSat radar because of the very poor vertical resolution of this radar $(\sim 500$ $\mathrm{m})$. Besides, a qualitative analysis of the profile shapes for this approach is somewhat subjective, which might cause problems for automation. It would be significantly more convenient to have a simple quantitative criterion for separating cloud profiles where the effects of drizzle can be neglected when estimating LWC from $Z_{e}$ and where drizzle causes unacceptable errors in radar-derived water content.

One such criterion is based on reflectivity thresholding (e.g., Frisch et al. 1995). Under this criterion, drizzle effects are neglected in particular cloud parts if reflectivities of these parts are less than some preset threshold, $Z_{\mathrm{et}}$. Frisch et al. (1995) considered thresholds of about -15 to $-17 \mathrm{dBZ}$ for marine stratocumulus observed near Madeira, Portugal. Using both the Doppler and $Z_{\mathrm{et}}$ approaches (though based on limited observations), they suggested that simple $Z_{\text {et }}$ thresholding can be used to effectively separate cloud parts with a strong drizzle effect from those when drizzle contributions are small.
In this study, we investigate the $Z_{\text {et }}$ thresholding approach with respect to the accuracy of radar reflectivityonly retrievals of LWC, which is mostly dominated by the cloud-size drops (Fox and Illingworth 1997). The general question posed here is as follows: what are the uncertainties and biases of reflectivity-only retrievals of water content for different reflectivity thresholding? Obviously, such simple thresholding does not guarantee the total absence of drizzle drops in a particular radar volume. Therefore, another question that can be asked is how severe can be drizzle effects for $Z_{e}$-based water content retrievals at different thresholds?

\section{Accuracies of MMCR retrievals of $L W P$}

Thresholding based on the profile maximum value of $Z_{e}$ is analyzed first. This is a simple thresholding approach applicable in a general situation when no information on clouds besides reflectivity is available. The height and time resolution of MMCR data in Fig. 2 are $45 \mathrm{~m}$ and $1 \mathrm{~min}$, respectively. Table 1 (second column) shows the percentage of the total number of cloud profiles in EPIC for which no reflectivity values $Z_{e}$ exceeded a given threshold $Z_{\text {et }}$. Six values of $Z_{\text {et }}$ were considered: $-15,-17,-19,-21,-23$, and $-25 \mathrm{dBZ}$. About one-half of all cloud profiles have all reflectivities less than $-15 \mathrm{dBZ}$, and about one-third of the profiles have all $Z_{e}<-17 \mathrm{dBZ}$. However, only $10 \%$ of the profiles are characterized by $Z_{e}$ values that are all less than $-25 \mathrm{dBZ}$. Attenuation effects (see section 5) were accounted for in these statistics.

The impact of drizzle on the correspondence between LWC and $Z_{e}$ depends on the thresholding level $Z_{\mathrm{et}}$. With the mean values for $N_{o}$ and $\sigma$ from Miles et al. (2000), relation (6) for marine clouds is

$$
\text { LWC }\left(\mathrm{g} \mathrm{m}^{-3}\right)=2.4 Z_{e}^{0.5}\left(\mathrm{~mm}^{6} \mathrm{~m}^{-3}\right) \text {. }
$$

This relation was applied to all profiles of $Z_{e}$ shown in Fig. 2. Because it was impossible to assess the accuracy of this relation for range-resolved values of $\mathrm{LWC}$, the accuracy assessment was done for the vertically integrated LWC, that is, LWP values. LWP was routinely and independently retrieved by the MWR collocated with the radar. MWR measurements have been used for several decades for retrieving LWP. LWP retrievals based on these measurements have been shown to compare well with both in situ aircraft and adiabatic estimates of cloud liquid, and so these retrievals can be considered quite robust for warm clouds in the absence of substantial precipitation (Westwater et al. 2001). The MWR retrievals were fine-tuned on a daily basis to ensure near-zero LWP values for clear-sky conditions. The resulting uncertainty of microwave radiometer retrievals

$\leftarrow$

FIG. 2. Time-height cross sections of the MMCR reflectivity profiles for 15 days of the EPIC 2001 cruise. Each frame also shows the cloud fraction for a particular day. The broken white line shows the cloud-base heights as indicated by the lidar ceilometer. 
TABLE 1. Biases $(B)$, relative standard deviations (RSDs), and median absolute errors (MAE) of radar LWP ${ }_{Z}$ estimates relative to the radiometer $\mathrm{LWP}_{R}$ at different thresholds (MMCR LWP estimates are integrals for entire profiles). Profile maximum value thresholding; $B$ $=\left\langle\left(\mathrm{LWP}_{Z}-\mathrm{LWP}_{R}\right) / \mathrm{LWP}_{R}\right\rangle \times 100 \%, \mathrm{RSD}=\left\langle\left(\mathrm{LWP}_{Z}-\mathrm{LWP}_{R}\right)^{2} / \mathrm{LWP}_{R}{ }^{2}\right\rangle^{0.5} \times 100 \%$, where angle brackets denote averaging.

\begin{tabular}{|c|c|c|c|c|c|c|c|}
\hline $\begin{array}{l}\text { Threshold } \\
Z_{\text {et }}(\mathrm{dBZ})\end{array}$ & $\begin{array}{l}\text { Percentage of tot } \\
\text { No. of profiles with } \\
\text { all } Z_{e}<Z_{\text {et }}\end{array}$ & $\begin{array}{c}B[(7)] \\
(\%)\end{array}$ & $\begin{array}{c}\operatorname{RSD}[(7)] \\
(\%)\end{array}$ & $\begin{array}{c}\text { MAE }[(7)] \\
(\%)\end{array}$ & $\begin{array}{c}B[(8)] \\
(\%)\end{array}$ & $\begin{array}{c}\operatorname{RSD}[(8)] \\
(\%)\end{array}$ & $\begin{array}{c}\text { MAE }[(8)] \\
(\%)\end{array}$ \\
\hline-15 & 50.6 & 19 & 85 & 34 & 97 & 174 & 85 \\
\hline-17 & 43.2 & 8 & 73 & 32 & 71 & 140 & 66 \\
\hline-19 & 34.6 & -3 & 62 & 31 & 46 & 109 & 53 \\
\hline-21 & 25.6 & -11 & 58 & 32 & 25 & 85 & 43 \\
\hline-23 & 17.0 & -15 & 53 & 45 & 7 & 53 & 40 \\
\hline-25 & 10.4 & -35 & 55 & 50 & -17 & 58 & 41 \\
\hline
\end{tabular}

is considered to be on the order of about $15 \mathrm{~g} \mathrm{~m}^{-2}$. The MWR retrievals were considered as the "ground truth" for the radar retrievals in the statistical comparisons given below.

Table 1 shows biases, relative standard deviations (RSDs), and median absolute errors (MAE) of radarderived LWP values in comparison with LWP from microwave radiometer retrievals. Note that MAE values are influenced by the biases. Comparisons were made based on 1-min averages. For each $Z_{\mathrm{et}}$ level, only the corresponding subset of measured profiles (shown in the second column) was used for calculating statistics. The integration of radar LWC retrievals was performed accounting for all radar gates with measurable echoes, including those below the cloud base as indicated by the ceilometer. In addition to relation (7), radar data were used to derive LWP values using an empirical relation for marine stratocumulus suggested by Fox and Illingworth (1997) for drizzle-free clouds:

$$
\text { LWC }\left(\mathrm{g} \mathrm{m}^{-3}\right)=9.3 Z_{e}^{0.64}\left(\mathrm{~mm}^{6} \mathrm{~m}^{-3}\right) \text {. }
$$

Relation (8) was obtained from the analysis of aircraft in situ drop measurements with both LWC and $Z_{e}$ calculated from the same aircraft samples.

It can be seen from Table 1 that the use of relation (7) provides a factor of about 2 uncertainty $(\mathrm{RSD} \approx$ $85 \%$ ) and a small positive bias of $19 \%$ in radar retrievals of LWP already for a relatively conservative thresholding value of $Z_{\mathrm{et}}=-15 \mathrm{dBZ}$. Statistically speaking, LWP for about one-half of all cloudy profiles $(\sim 50.6 \%)$ can be retrieved with this uncertainty using relation (7). For about one-third of all profiles (i.e., for profiles that passed $-19 \mathrm{dBZ}$ thresholding), this relation provides almost unbiased values of LWP with the uncertainty characterized by the relative standard deviation of about $62 \%$. For lower thresholding levels $Z_{\mathrm{e}}$, relation (7) produces progressively negative biases. It becomes more evident as drizzle contributions to $Z_{e}$ become progressively smaller because the thresholding value $Z_{\mathrm{et}}$ is decreased.

For the $-15-\mathrm{dBZ}$ threshold, relation (8) provides LWP values that are biased high by a factor of 2 , and the corresponding uncertainties are very large. Both the bias and the RSD for this relation diminish as $Z_{\mathrm{et}}$ decreases to about $-23 \mathrm{dBZ}$. At this thresholding level, relation (8) provides almost unbiased values of LWP and low RSD (see Table 1). For $Z_{\mathrm{et}} \leq-23 \mathrm{dBZ}$, this relation provides less biased results when compared with relation (7). However, only $17 \%$ of all cloudy profiles satisfy the requirement $Z_{\mathrm{et}} \leq-23 \mathrm{dBZ}$. Relation (7) provides better estimates for $Z_{\mathrm{et}}>-23 \mathrm{dBZ}$, which covers more profiles. The greater negative biases for (7) at small values of $Z_{\mathrm{et}}$ indicate that this relation somewhat underestimates LWC for small cloud drops. For larger $Z_{\mathrm{et}}$ values, this is compensated by effects of larger drizzle drops and drops that are in a transition regime from cloud size to drizzle size.

Some general underestimation of total LWP by (7) is seen more clearly if the vertical integration of radarderived LWC values is performed only for the data above cloud base, as shown by the ceilometer. Table 2 shows comparisons of radar and microwave radiometer estimates of LWP for this case. It can be seen that (7) underestimates LWP for the whole range of $Z_{\mathrm{et}}$, though this relation still provides a better fit [cf. (8)] for higher thresholds $\left(Z_{\mathrm{et}}>-19 \mathrm{dBZ}\right)$. Note that for this type of

TABLE 2. Same as Table 1, but MMCR LWP estimates are integrals from the cloud base.

\begin{tabular}{|c|c|c|c|c|c|c|c|}
\hline $\begin{array}{l}\text { Threshold } \\
Z_{\text {et }}(\mathrm{dBZ})\end{array}$ & $\begin{array}{l}\text { Percentage of tot } \\
\text { No. of profiles with } \\
\text { all } Z_{e}<Z_{\mathrm{et}}\end{array}$ & $\begin{array}{c}B[(7)] \\
(\%)\end{array}$ & $\begin{array}{c}\operatorname{RSD}[(7)] \\
(\%)\end{array}$ & $\begin{array}{c}\text { MAE }[(7)] \\
(\%)\end{array}$ & $\begin{array}{c}B[(8)] \\
(\%)\end{array}$ & $\begin{array}{c}\mathrm{RSD}[(8)] \\
(\%)\end{array}$ & $\begin{array}{c}\text { MAE [(8)] } \\
(\%)\end{array}$ \\
\hline-15 & 50.6 & -15 & 60 & 31 & 44 & 115 & 56 \\
\hline-17 & 43.2 & -20 & 58 & 29 & 29 & 95 & 45 \\
\hline-19 & 34.6 & -26 & 57 & 31 & 14 & 76 & 37 \\
\hline-21 & 25.6 & -30 & 58 & 37 & 9 & 65 & 33 \\
\hline-23 & 17.0 & -32 & 60 & 55 & -9 & 55 & 45 \\
\hline-25 & 10.4 & -45 & 68 & 62 & -28 & 58 & 47 \\
\hline
\end{tabular}


TABLE 3. Same as Table 1, but thresholding is based on reflectivities in the lower half of the cloud.

\begin{tabular}{|c|c|c|c|c|c|c|c|}
\hline $\begin{array}{l}\text { Threshold } \\
Z_{\text {et }}(\mathrm{dBZ})\end{array}$ & $\begin{array}{l}\text { Percentage of tot } \\
\text { No. of profiles with } \\
\text { all } Z_{e}<Z_{\text {et }}\end{array}$ & $\begin{array}{c}B[(7)] \\
(\%)\end{array}$ & $\begin{array}{c}\operatorname{RSD}[(7)] \\
(\%)\end{array}$ & $\begin{array}{c}\text { MAE }[(7)] \\
(\%)\end{array}$ & $\begin{array}{c}B[(8)] \\
(\%)\end{array}$ & $\begin{array}{c}\operatorname{RSD}[(8)] \\
(\%)\end{array}$ & $\begin{array}{c}\text { MAE }[(8)] \\
(\%)\end{array}$ \\
\hline-15 & 53.5 & 22 & 92 & 41 & 114 & 209 & 93 \\
\hline-17 & 46.8 & 11 & 80 & 39 & 95 & 164 & 71 \\
\hline-19 & 37.6 & 3 & 71 & 37 & 54 & 119 & 63 \\
\hline-21 & 29.8 & -5 & 60 & 34 & 36 & 99 & 52 \\
\hline-23 & 20.8 & -9 & 55 & 46 & 24 & 72 & 48 \\
\hline-25 & 13.7 & -25 & 56 & 47 & 7 & 60 & 43 \\
\hline
\end{tabular}

comparison, drizzle contributions to the radar-derived LWP below the ceilometer cloud base are ignored. Although these contributions to the MWR measurements of LWP expected to be small (e.g., about $10 \mathrm{~g} \mathrm{~m}^{-2}$ for a 800-m uniform drizzle layer of $2 \mathrm{~mm}^{-1 a y^{-1}}$; Rosenberg 1972), some part of the biases in LWP radar estimates can be explained by the LWP present below the ceilometer cloud bases. Another plausible and potentially more significant factor to explain some negative biases of both (7) and (8) for low $Z_{\mathrm{et}}$ values, when integrating from the cloud bases to cloud tops, is some overestimation of cloud-base heights by the ceilometer relative to heights from the radar.

Comparing Tables 1 and 2 shows that the exclusion of cloud parts below the ceilometer cloud base results in about a $35 \%-40 \%$ decrease in biases of the radarderived LWP using (7) at $Z_{\mathrm{et}}=-15 \mathrm{dBZ}$. This decrease diminishes with $Z_{\mathrm{et}}$, and it is only about $10 \%$ at $Z_{\mathrm{et}}=$ $-25 \mathrm{dBZ}$. Despite some negative biases, the use of (7) provides a decent approximation for LWP. The observed biases are within the scope of changes expected from uncertainties in the coefficient $a_{1}\left(N_{o}, \sigma\right)$ in this relation [see (6)], which are due to natural variations in $N_{o}$ and $\sigma$. For example, either the change of $\sigma$ to 0.3 from the mean value of 0.38 or the change of $N_{o}$ to $130 \mathrm{~cm}^{-3}$ from the mean value of $75 \mathrm{~cm}^{-3}$ can both result in the increase of $a_{1}$ by about $30 \%$, which would effectively eliminate the negative bias in radar estimates of LWP using the theoretical relation (6).

Though, the maximum reflectivity value profile thresholding discussed above is a convenient way, based on $Z_{e^{-}}$-only data, to select profiles for which the influence of drizzle on LWC retrievals can generally be neglected (within specified uncertainties that depend on the $Z_{\mathrm{et}}$ value), it does not ensure eliminating profiles that con- tain drizzle. The recent work by Wang and Geerts (2003) suggests that the physical threshold between drizzle and drizzle-free profiles is crisply defined only in the lower half of the cloud. Because cloud-base information in EPIC was available from the ceilometer (note that cloudbase information is not available on many other occasions), the thresholds were also applied solely to the regions above the ceilometer base, but in only the lower half of the cloud. The corresponding results are summarized in Tables 3 and 4. More reflectivity profiles pass the lower-cloud-half thresholding, in comparison with the maximum value thresholding, though the total increase in the profiles for each $Z_{\mathrm{et}}$ is relatively modest (cf. second columns in Tables 1 and 3). For the whole EPIC dataset, biases and RSDs for these two thresholding approaches are not drastically different, which, in part, can be explained by the fact that quite often highest reflectivities were observed in the lower half of the cloud, even in situations in which drizzle effects are supposedly rather limited (e.g., around 2000 UTC on 11 October, and many other periods in Fig. 2). This can be conceivably due to possible overestimation of cloudbase heights by the ceilometer (relative to radar heights), which underlines potential ambiguities caused by independent estimates of cloud bases.

Illustrations of comparisons between microwave radiometer and radar reflectivity-based retrievals of LWP are given in Figs. 3, 4, and 5. The upper frames in these figures correspond to the radar data representing the entire profiles, and the lower frames correspond to the integration of the radar data from the ceilometer base to the top of the echo. For a very limited drizzle case of 23 October 2001 (Fig. 3), all reflectivities did not exceed $-17 \mathrm{dBZ}$, and $88 \%$ of all the profiles had no reflectivities greater than $-23 \mathrm{dBZ}$. There is a relatively

TABLE 4. Same as Table 2, but thresholding is based on reflectivities in the lower half of the cloud.

\begin{tabular}{cccccccc}
\hline \hline Threshold & $\begin{array}{c}\text { Percentage of tot } \\
\text { No. of profiles with } \\
\text { all } Z_{e}<Z_{\mathrm{et}}\end{array}$ & $\begin{array}{c}B[(7)] \\
(\%)\end{array}$ & $\begin{array}{c}\text { RSD [(7)] } \\
(\%)\end{array}$ & $\begin{array}{c}\text { MAE [(7)] } \\
(\%)\end{array}$ & $\begin{array}{c}B[(8)] \\
(\%)\end{array}$ & $\begin{array}{c}\text { RSD [(8)] } \\
(\%)\end{array}$ & $\begin{array}{c}\text { MAE [(8)] } \\
(\%)\end{array}$ \\
\hline-15 & 53.5 & -11 & 78 & 44 & 66 & 134 & 55 \\
-17 & 46.8 & -15 & 77 & 42 & 58 & 114 & 56 \\
-19 & 37.6 & -18 & 72 & 39 & 26 & 96 & 56 \\
-21 & 29.8 & -22 & 68 & 47 & 15 & 59 & 48 \\
-23 & 20.8 & -23 & 63 & 44 & 5 & 59 & 38 \\
-25 & 13.7 & -31 & 66 & 43 & -6 & 59 & \\
\hline
\end{tabular}


a)

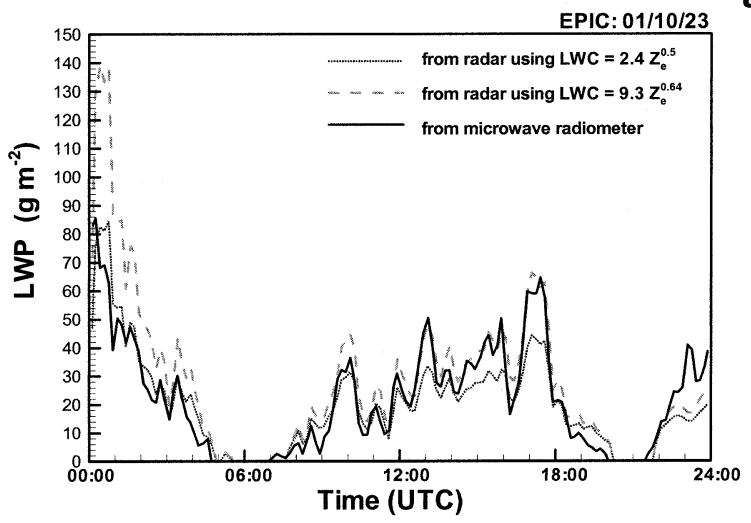

b)

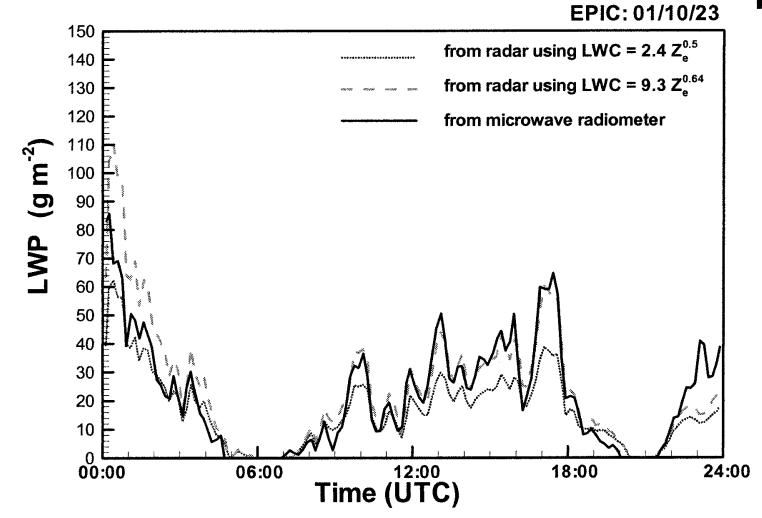

FIG. 3. Comparisons of LWP derived from the microwave radiometer data with different radar estimators for 23 Oct 2001 for MMCR measurements. Radar LWP values are obtained (a) by integrating estimated LWC along the whole measured radar profile and (b) from the ceilometer cloud base to the top of the echo.

good agreement between radar-based LWP values derived using relation (7) and the microwave radiometer data for the entire observational period on this date. LWP values retrieved with the use of empirical relation (8) noticeably overestimate radiometrically derived values for the period between 0000 and 0300 UTC, when the measured reflectivities were the highest. For the rest of the day, (8) also provides a decent approximation for the radiometer LWP. It even outperforms the relation (7) results between 1300 and 1800 UTC when observed radar reflectivities were relatively small. The difference between data in Figs. $3 \mathrm{a}$ and $3 \mathrm{~b}$ is small, indicating rather insignificant contributions from areas below the ceilometer cloud base.

Figure 4 shows LWP comparisons for 15 October, a case with moderate drizzle most of the day. This day was characterized by the $100 \%$ cloud fraction. The percentages of measured profiles that satisfied the maximum value thresholding at $-15,-17,-19,-21,-23$, and $-25 \mathrm{dBZ}$ for this day were $78 \%, 67 \%, 52 \%, 30 \%$, $15 \%$, and $6 \%$, respectively. During the period between

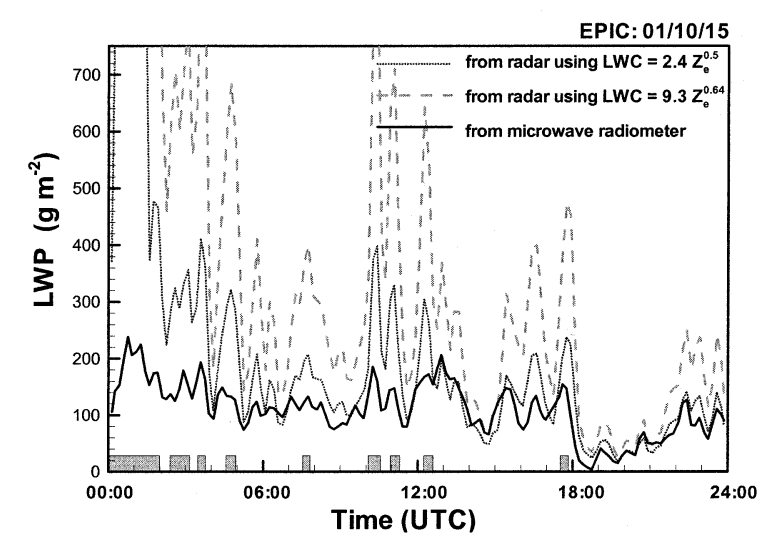

a)

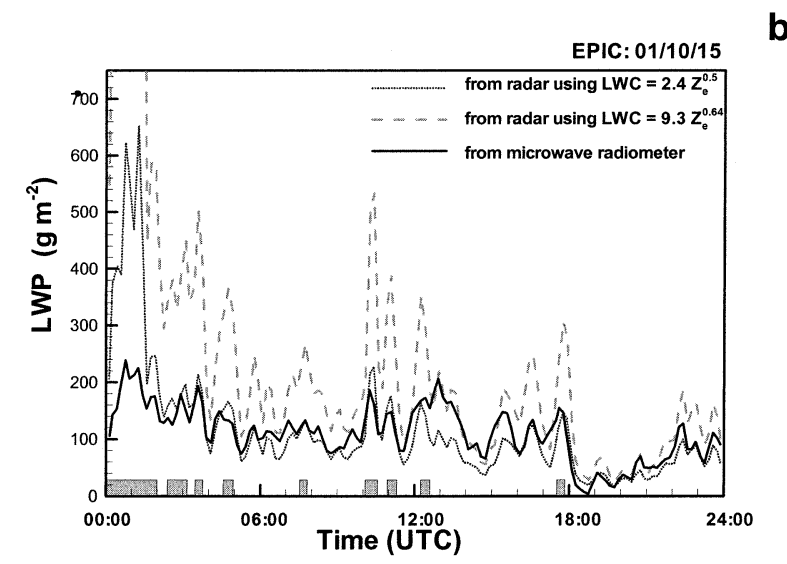

FIG. 4. Same as Fig. 3, but for 15 Oct 2001. Gray bars on the time axis indicate periods when radar profiles contained $Z_{e}>-15 \mathrm{dBZ}$.

0000 and 0200 UTC, which was characterized by stronger drizzle, the measured reflectivities are heavily biased by drizzle drops, and reflectivity-based retrievals significantly overestimate LWP. After about 0600 UTC, reflectivities are generally small and the use of (7) provides a good approximation of LWP, especially when the LWP is calculated by integrating LWC values from the ceilometer cloud base (Fig. 4b). The use of (8) generally results in overestimating LWP on this day. This event is also characterized by a larger improvement of LWP radar estimates if the integration is carried out from the ceilometer cloud base.

An example of a day with a heavy-drizzle event during local nighttime period is 22 October 2001 (Fig. 5). Relatively good agreement between radar and MWR retrievals of LWP is seen outside this period and a few shorter periods of higher reflectivity, which are marked in Fig. 5 as those that did not pass $-15-\mathrm{dBZ}$ thresholding. For this case, results obtained with (7) are somewhat closer to the MWR data than those obtained with the use of (8). An improvement is evident if the radar data integration is performed from the ceilometer cloud bases rather than for the whole observed profiles. 

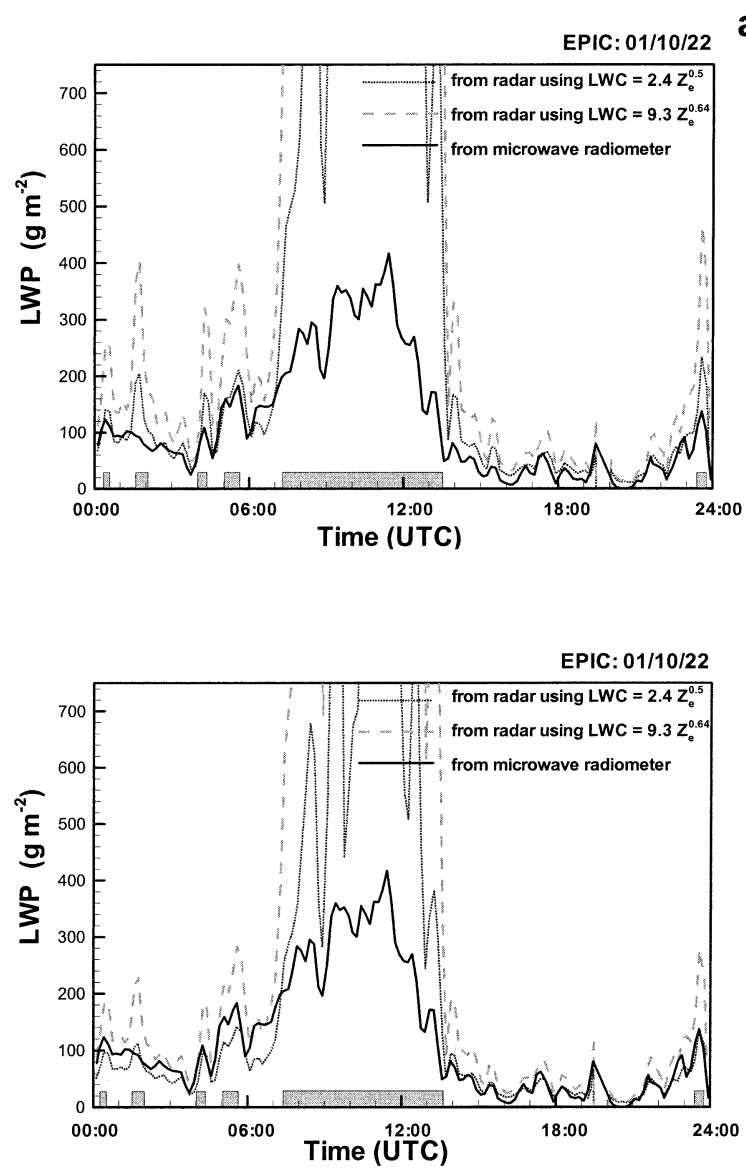

FIG. 5. Same as Fig. 3, but for 22 Oct 2001. Gray bars on the time axis indicate periods when radar profiles contained $Z_{e}>-15 \mathrm{dBZ}$.

Comparing data in Tables 1 and 2 (and Tables 3 and 4) provides a means for quantitatively assessing improvements that can be attributed to accounting for the cloudbase heights for the whole 15-day period.

As mentioned above, the generally good agreement between the radar and radiometer data for specific thresholds of $Z_{\text {et }}$ does not guarantee the absence of drizzle for cloud profiles that passed these thresholds. It shows, however, that the low-reflectivity drizzle contributions may not result, on average, in substantial errors when using radar reflectivity-based retrievals of water content with proper reflectivity thresholding.

\section{CloudSat implications}

For some cloud content retrievals from the ground, W-band radars have been used (e.g., Clothiaux et al. 1995; Sassen and Liao 1996). The CloudSat nadir-pointing 94-GHz spaceborne radar will be the first W-band radar to study clouds from space. It will have a sensitivity of about $-28.5 \mathrm{dBZ}$ near the surface and a pulse length of about $500 \mathrm{~m}$ (Stephens et al. 2002). The radar pulse will be overlapped to result in 240-m sampling intervals. Averaging of 0.32 -s time intervals will pro- vide an oblong effective field of view with a horizontal resolution of about 1.5 (across track) and $3.5 \mathrm{~km}$ (along track). At the $94-\mathrm{GHz}$ frequency, there will be a significant two-way attenuation of radar signals, especially in humid tropical atmospheres. A substantial part of this attenuation comes from atmospheric gases, especially water vapor. At the frequency of $35 \mathrm{GHz}$, the gaseous attenuation usually constitutes only fractions of $1 \mathrm{~dB}$ and is often neglected. At the CloudSat frequency, this attenuation will degrade the radar capability, for which it needs to be accounted. To investigate the sensitivity and retrieval potential of the CloudSat radar to the kinds of marine stratiform clouds observed during EPIC, this section models the CloudSat measurements based on EPIC observations and assesses expected retrieval uncertainties.

\section{a. Attenuation corrections}

The gaseous absorption at both 94- and 35-GHz frequency bands is determined by water vapor and, to a lesser extent, oxygen $\left(\mathrm{O}_{2}\right)$. While the oxygen component to the total attenuation exhibits only modest variability, because $\mathrm{O}_{2}$ is a well-mixed gas, the attenuation by water vapor can vary significantly. For a given temperature and pressure vertical distributions, the two-way attenuation in water vapor $A_{\mathrm{H} 2 \mathrm{O}}$ is proportional to the water vapor amount (WVA). The dependence of $A_{\mathrm{H} 2 \mathrm{O}}$ on pressure and temperature was modeled by variations of these characteristics in a reasonable range of their natural changes. The results of modeling, using the absorption models from Stepanenko et al. (1987), were then approximated by an exponential function as a function of height $h$ (km MSL),

$$
\begin{aligned}
A_{\mathrm{H}_{2} \mathrm{O}}(\mathrm{dB}) \approx & A_{f} \operatorname{WVA}\left(P_{o} / 1013\right)\left(293 / T_{o}\right)^{1.5} \\
& \times[1-\exp (-0.42 h)],
\end{aligned}
$$

where $P_{o}$ and $T_{o}$ are the surface pressure and temperature in hectopascals and kilometers, correspondingly, WVA is in kilograms per meter squared, and $A_{f}=0.077$ (for $94 \mathrm{GHz}$ ) or $A_{f}=0.013$ (for $35 \mathrm{GHz}$ ). The oxygen component of the two-way attenuation, as a function of height for $h<15 \mathrm{~km}$, can be approximated by polynomial curves:

$$
\begin{aligned}
A_{\mathrm{O}_{2}}(\mathrm{~dB}) \approx & \left(P_{o} / 1013\right)^{2}\left(293 / T_{o}\right)^{2} \\
& \times\left[\left(7.02 \times 10^{-2} h\right)-\left(4.81 \times 10^{-3} h^{2}\right)\right. \\
& \left.\quad+\left(1.22 \times 10^{-4} h^{3}\right)\right] \quad(\text { for } 94 \mathrm{GHz})(10)
\end{aligned}
$$

and

$$
\begin{aligned}
A_{\mathrm{O}_{2}}(\mathrm{~dB})= & \left(P_{o} / 1013\right)^{2}\left(293 / T_{o}\right)^{2} \\
\times & {\left[\left(5.36 \times 10^{-2} h\right)-\left(3.66 \times 10^{-3} h^{2}\right)\right.} \\
& \left.\quad+\left(9.95 \times 10^{-5} h^{3}\right)\right] \quad(\text { for } 35 \mathrm{GHz}) .
\end{aligned}
$$

For spaceborne radars, approximations in terms of $h$ (i.e., the path from the surface to the considered height) 
given above have to be reworked in terms of paths from top of the atmosphere.

It is well known that the attenuation in liquid water clouds depends on cloud temperature (e.g., Stepanenko et al. 1987). For the purpose of this study, the following approximations were derived for the two-way attenuation in liquid water $A_{\mathrm{LW}}$ :

$$
\begin{gathered}
A_{\mathrm{LW}}(\mathrm{dB}) \approx 7.56 \times \mathrm{LWP}(h)[1.0+(293-T) \times 0.012] \\
\quad(\text { for } 94 \mathrm{GHz}) \quad \text { and } \\
A_{\mathrm{LW}}(\mathrm{dB}) \approx 1.27 \times \mathrm{LWP}(h)[1.0+(293-T) \times 0.03]
\end{gathered}
$$$$
\text { (for } 35 \mathrm{GHz} \text { ), }
$$

where $\operatorname{LWP}(h)$ is the one-way $\operatorname{LWP}\left(\mathrm{kg} \mathrm{m}^{-2}\right)$ to the considered height $h$, and $T$ is the cloud temperature in kelvins.

\section{b. Modeling of CloudSat measurements of EPIC clouds}

The time-height cross sections of MMCR measurements in EPIC were used to simulate CloudSat radar measurements. It was assumed that the Rayleigh-type scattering is still valid at $94 \mathrm{GHz}$ for observed clouds. The appropriate vertical range resolution, sampling, and attenuation corrections were applied for these simulations. Effects of partial beam filling in the vertical were accounted for. It was assumed also that the center of the first range gate is positioned at $350 \mathrm{~m}$ above the ground to avoid/reduce unwanted ground contaminations in the radar returns. Figure 6 shows the EPIC 2001 clouds as they would be "detected" by the CloudSat radar. One-minute resolution of original radar profiles was initially preserved. It can be seen by comparing Figs. 2 and 6 that the CloudSat radar would detect most of the cloud profiles that contain drizzle. With the sensitivity of $-28.5 \mathrm{dBZ}$, it would have problems detecting clouds for which the drizzle contribution is either very small or absent. Examples of such clouds are those on 23 October 2001 when CloudSat would detect about $8.5 \%$ of cloud profiles, and on 24 October 2001 when only $5.3 \%$ of cloudy profiles would be seen by the CloudSat radar. Each frame in Fig. 6 contains the information on the cloud fraction for a given day from MMCR measurements and the relative cloud fraction, that is, the percentage of MMCR profiles "detected" by CloudSat (denoted as "cls cf" in Fig. 6). The average percentage of all clouds that would be detected by CloudSat for the whole observational period is $75 \%$. This percentage is somewhat larger than the $62 \%$ estimate by Uttal and Kropfli (2001) for North Atlantic clouds. Note, however, that Uttal and Kropfli (2001) did not account for 240-m sampling and considered all cloud types (including cirrus) observed during the Atlantic Stratocumulus Transition Experiment (ASTEX) field experiment.

The maximum-value reflectivity thresholding procedure described in section 4 was applied to the simulated spaceborne measurements. The percentage of the CloudSat profiles that satisfy reflectivity thresholding at each level of $Z_{\mathrm{et}}$ is given in the second column of Table 5. Comparing Tables 1 and 5 shows that the relative number of profiles satisfying each $Z_{\mathrm{et}}$ condition is about the same for MMCR and CloudSat measurements. The absolute number of profiles is obviously smaller for spaceborne measurements because the CloudSat radar would detect only $75 \%$ of cloudy profiles. The coarser resolution and limited sensitivity of the CloudSat radar also results in some distortion of cloudy profiles. This distortion, however, is smaller in the regions with relatively heavy drizzle. Lower-cloud-half thresholding provides results (not shown) that are practically identical to those using maximum-value thresholding because, for the CloudSat resolution, higher reflectivities are almost always observed in the lower half of the cloud (see Fig. 6 , and the corresponding ceilometer cloud bases in Fig. 2).

LWP values using estimators (7) and (8) were calculated from the simulated CloudSat reflectivity profiles. Corrections for partial attenuation of radar signals were accounted for in these retrievals. Table 5 shows the uncertainty statistics of radar LWP retrievals in comparison with microwave radiometer data in cases for which the radar-derived LWC values were integrated over the entire reflectivity profiles. As compared with results for the MMCR high-resolution measurements, CloudSat reflectivity-only-based retrievals would significantly overestimate LWP for higher thresholds of $Z_{\mathrm{et}}$, especially if estimator (8) is used. For lower thresholds, relation (7) provides generally acceptable results, although a relatively small number of cloud profiles would pass these thresholds. By comparing data presented in Table 1 and 5 it can be seen that the relative quality of LWP radar estimates obtained with relation (7) is very similar for MMCR and CloudSat measurements if the satellite radar uses a threshold that is $8 \mathrm{~dB}$ lower (e.g., $-15 \mathrm{dBZ}$ for the MMCR measurements and $-23 \mathrm{dBZ}$ for the CloudSat measurements). The bias of LWP from CloudSat-simulated measurements monotonically decreases as $Z_{\mathrm{et}}$ diminishes; LWP values are practically unbiased at $Z_{\mathrm{et}} \approx-25 \mathrm{dBZ}$. This monotonic behavior can, probably, be used to "tune" low CloudSat estimates of LWP derived at higher thresholds. By doing this, the applicability range for spaceborne measurements can be increased without providing unrealistically high retrieval values.

FIG. 6. Time-height cross sections of the CloudSat radar-simulated radar reflectivity profiles for 15 days of the EPIC 2001 cruise. Each frame also shows the MMCR cloud fraction for a particular day and the percentage of MMCR profiles detectable by CloudSat (cls cf). 

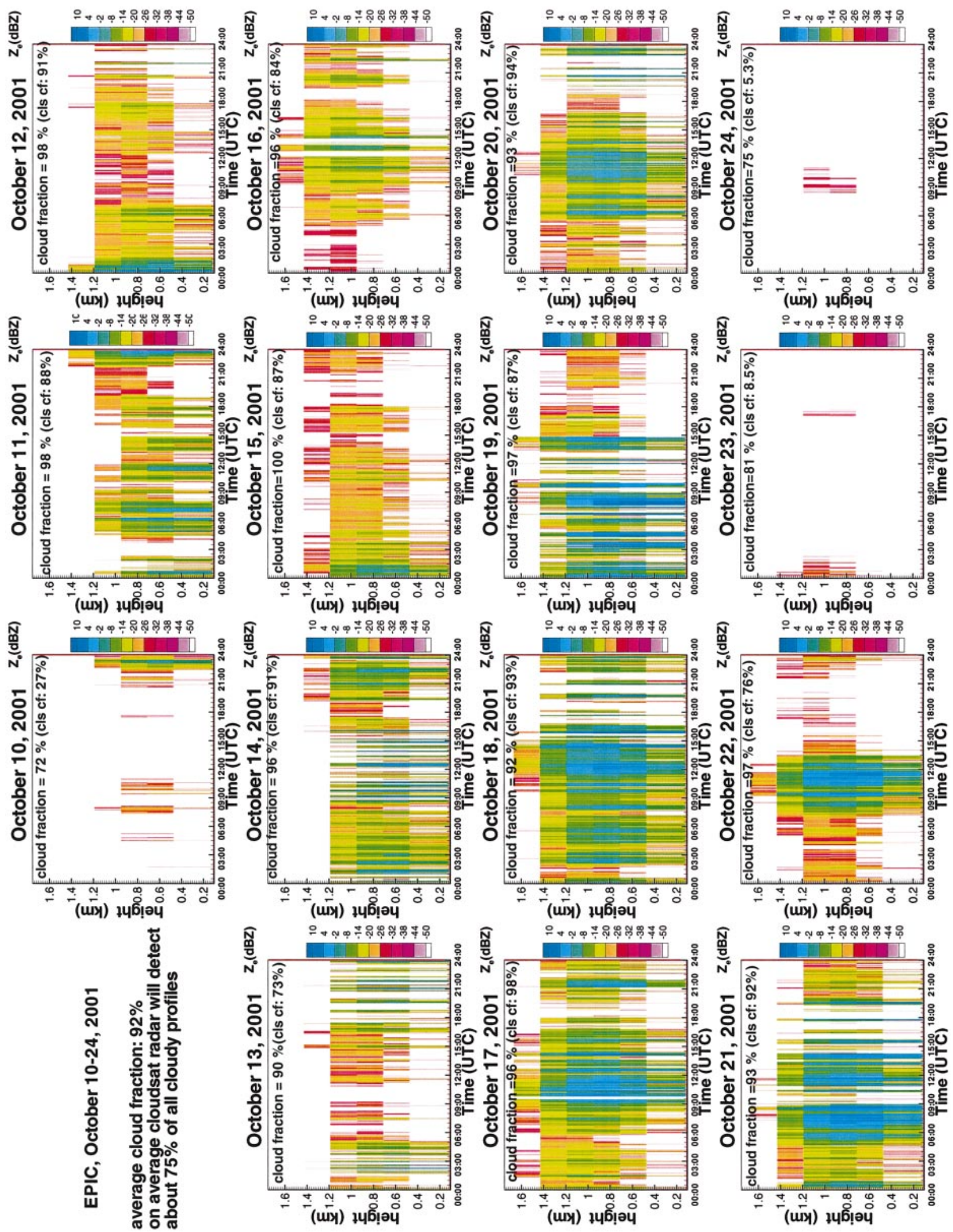
TABLE 5. Same as Table 1, but for simulated CloudSat estimates.

\begin{tabular}{|c|c|c|c|c|c|c|c|}
\hline $\begin{array}{l}\text { Threshold } \\
Z_{\text {et }}(\mathrm{dBZ})\end{array}$ & $\begin{array}{l}\text { Percentage of tot } \\
\text { No. of profiles with } \\
\text { all } Z_{e}<Z_{\mathrm{et}}\end{array}$ & $\begin{array}{c}B[(7)] \\
(\%)\end{array}$ & $\begin{array}{c}\mathrm{RSD}[(7)] \\
(\%)\end{array}$ & $\begin{array}{c}\text { MAE }[(7)] \\
(\%)\end{array}$ & $\begin{array}{c}B[(8)] \\
(\%)\end{array}$ & $\begin{array}{c}\operatorname{RSD}[(8)] \\
(\%)\end{array}$ & $\begin{array}{c}\text { MAE }[(8)] \\
(\%)\end{array}$ \\
\hline-15 & 52 & 73 & 156 & 61 & 212 & 343 & 161 \\
\hline-17 & 45 & 59 & 135 & 56 & 175 & 285 & 136 \\
\hline-19 & 38 & 45 & 116 & 41 & 144 & 235 & 119 \\
\hline-21 & 30 & 31 & 99 & 39 & 114 & 193 & 90 \\
\hline-23 & 21 & 17 & 83 & 36 & 85 & 152 & 70 \\
\hline-25 & 10 & 4 & 72 & 36 & 56 & 121 & 53 \\
\hline
\end{tabular}

Table 6 presents results of LWP comparisons when the vertical integration of radar-derived LWC values is taken only above the cloud base as indicated by the ceilometer (i.e., the lowest accounted resolution gate was the one with its center higher than the ceilometer cloud base). Comparing data from Tables 5 and 6 shows that knowledge of cloud bases results in better radar estimates of LWP for almost all thresholds of $Z_{\mathrm{et}}$. The heights of cloud bases are not readily available from spaceborne measurements, however. In the absence of cloud-base information, statistically accounting for the spaceborne measurement bias, as mentioned above, may be a viable option for CloudSat radar measurements.

As for MMCR measurements, detailed comparisons between CloudSat-simulated retrievals and microwave radiometer estimates of LWP are given for the $23 \mathrm{Oc}-$ tober (Fig. 7), 15 October (Fig. 8), and 22 October (Fig. 9 ) cases. Most of the 23 October cloud would not be detected by the CloudSat radar, except for the first $2 \mathrm{~h}$ of this event and a short period between 1700 and 1800 UTC. The agreement between the radar and radiometer data from midnight to around 0100 UTC is quite similar for both MMCR and CloudSat observations, although past 0100 UTC, CloudSat estimates degrade rapidly because of the resolution and sensitivity issues. For the 15 October 2001 case, CloudSat would detect a significant portion $(\sim 87 \%)$ of cloudy profiles; however, it would miss almost one-half of the cloud after 1500 UTC on 22 October. For certain observational periods during 15 and 22 October, spaceborne radar retrievals with the use of (7) would provide reasonable estimates of LWP. Knowledge of the cloud-base heights would generally improve these estimates (cf. Figs. 7a and 7b, Figs. 8a and $8 \mathrm{~b}$, and Figs. $9 \mathrm{a}$ and $9 \mathrm{~b}$ ). To better match the spaceborne radar field of view for low advection rates,
CloudSat measurements were also simulated using the 3-min resolution of the original MMCR data. The radarderived LWP estimates were then compared with the microwave radiometer estimates with the same temporal resolution. The results were only slightly changed from those presented in Tables 5 and 6 and are not shown here.

\section{Summary and conclusions}

Presence of drizzle in marine stratiform clouds impedes the use of reflectivity-only techniques to estimate cloud parameters. Based on an experimental data collected in such clouds by a shipborne $35-\mathrm{GHz}$ radar and microwave radiometer during the EPIC 2001 experiment, accuracies of the liquid water path values derived only from the radar reflectivity measurements were evaluated. Cloud radar estimates of LWP were obtained by vertically integrating $L W C$ values derived from LWC$Z_{e}$ relations. A theoretical $\mathrm{LWC}-Z_{e}$ relation specifically tailored for marine stratiform clouds (7) and one derived empirically for drizzle-free clouds (8) were used in this study.

Radar reflectivity thresholding is a possible way to identify observed reflectivity profiles for which the influence of drizzle causes unacceptable biases in cloud parameter retrievals. For high-resolution radar measurements, even a relatively high threshold of $Z_{\mathrm{et}}=-15$ $\mathrm{dBZ}$, for which about one-half of all cloud scenes satisfy, provides a modest $19 \%$ bias and about a factor of 2 uncertainty in $Z_{e}$-only LWP estimates if relation (7) is used. Uncertainties the radar retrievals generally diminish as the thresholding level $Z_{\text {et }}$ decreases, though some negative biases are observed at lower values of $Z_{\mathrm{et}}$. These negative biases indicate that (7) and, to a

TABLE 6. Same as Table 5, but CloudSat estimates are LWC integrals from the cloud base.

\begin{tabular}{cccccccc}
\hline \hline Threshold & $\begin{array}{c}\text { Percentage of tot } \\
\text { No. of profiles with } \\
Z_{\mathrm{et}}(\mathrm{dBZ})\end{array}$ & $\begin{array}{c}B[(7)] \\
\text { all } Z_{e}<Z_{\mathrm{et}}\end{array}$ & $\begin{array}{c}\text { RSD [(7)] } \\
(\%)\end{array}$ & $\begin{array}{c}\text { MAE [(7)] } \\
(\%)\end{array}$ & $\begin{array}{c}B[(8)] \\
(\%)\end{array}$ & $\begin{array}{c}\text { RSD [(8)] } \\
(\%)\end{array}$ & $\begin{array}{c}\text { MAE [(8)] } \\
(\%)\end{array}$ \\
\hline-15 & 52 & 13 & 101 & 42 & 111 & 218 & 97 \\
-17 & 45 & 9 & 89 & 37 & 92 & 181 & 84 \\
-19 & 38 & 2 & 82 & 36 & 85 & 154 & 78 \\
-21 & 30 & -5 & 72 & 35 & 55 & 129 & 69 \\
-23 & 21 & -12 & 64 & 33 & 38 & 103 & 59 \\
-25 & 10 & -21 & 62 & 32 & 20 & 88 & 49 \\
\hline
\end{tabular}


a)
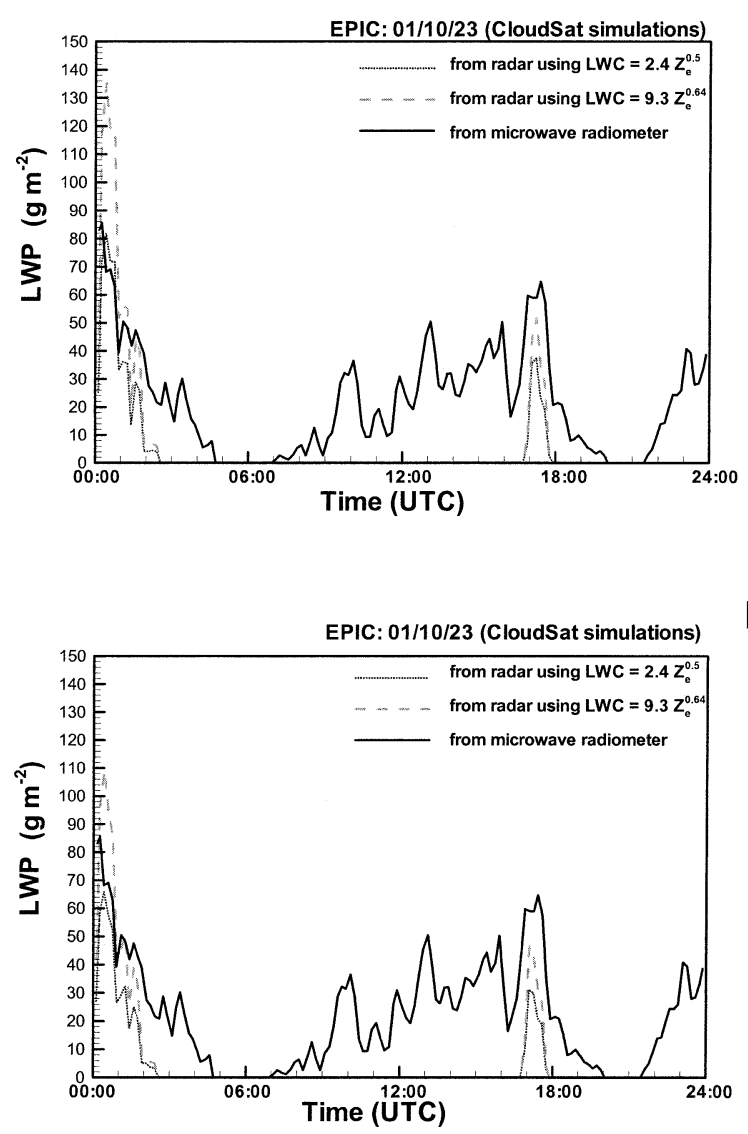

FIG. 7. Comparisons of LWP derived from the microwave radiometer data with different radar estimators for 23 Oct 2001 (CloudSatsimulated measurements). Radar LWP values are obtained (a) by integrating estimated LWC along the whole measured radar profile, and (b) from the ceilometer cloud base to the top of the echo.

lesser extent, (8) underestimate cloud content for small drop populations. The percentage of cloud profiles with all reflectivities less than $Z_{\text {et }}$ gradually decreases from about $50 \%$ to about $10 \%$, as $Z_{\text {et }}$ diminishes from -15 to $-25 \mathrm{dBZ}$. If the cloud-base heights are known from independent measurements, the exclusion of radar measurements in the areas below the ceilometer generally improves radar estimates of LWP for $Z_{\mathrm{et}} \gtrsim-19 \mathrm{dBZ}$. Overall, relation (7) performs better than (8), in part, because of its lesser susceptibility to the presence of drizzle (due to a smaller exponent, i.e., 0.5 vs 0.64 ). Maximum reflectivity value thresholding and lowercloud-half thresholding provided close results for the considered dataset of reflectivities and ceilometer cloud bases.

Because of sensitivity, partial attenuation, and vertical resolution issues, the prospective CloudSat spaceborne radar estimates of LWP based on reflectivity alone will be significantly less accurate in comparison with the ground-based MMCR measurements. The total fraction of marine stratiform clouds detectable by CloudSat would be about $75 \%$, and most of the nondrizzling

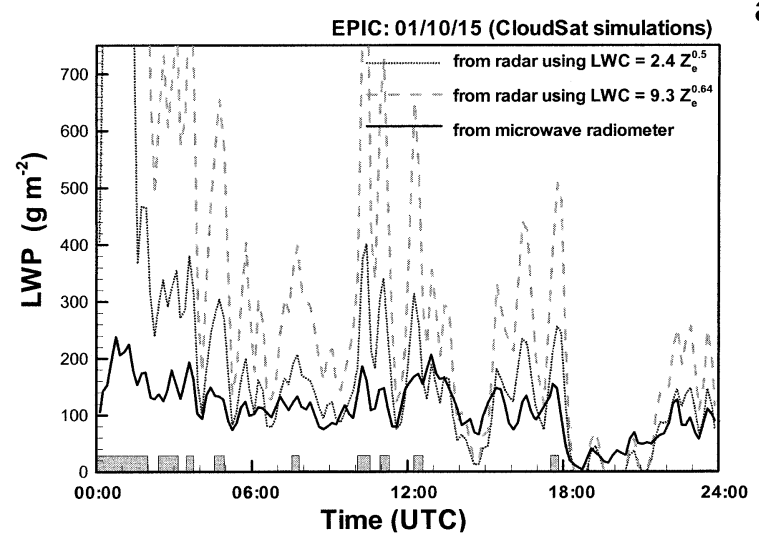

a)

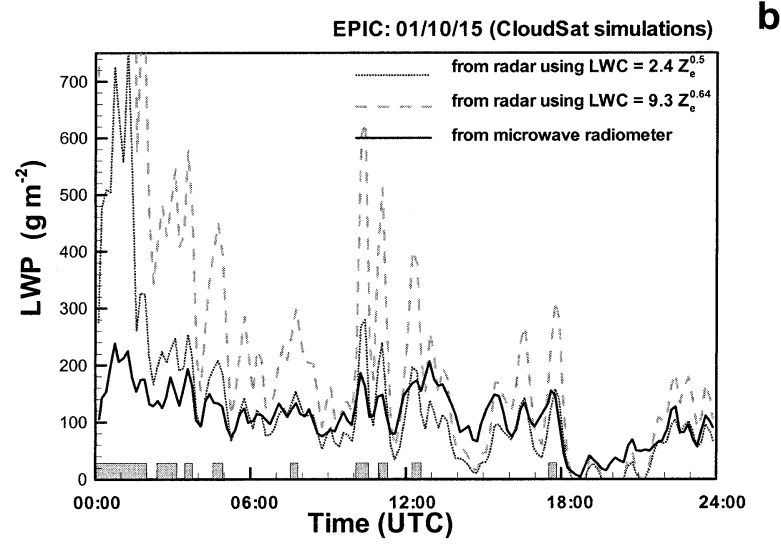

FIG. 8. Same as Fig. 7, but for 15 Oct 2001. Gray bars on the time axis indicate periods when radar profiles contained $Z_{e}>-15 \mathrm{dBZ}$.

clouds will be missed. For drizzling clouds at the same thresholding levels $Z_{\mathrm{e}}$, CloudSat estimates of LWP will have biases shifted to larger positive values in comparison with MMCR estimates because more cloud profiles with heavier drizzle will pass thresholding (for a particular $Z_{\mathrm{et}}$ value), chiefly due to partial beam-filling effects. Accounting for the CloudSat biases (in a statistical sense) given the gradual trend of these biases to diminish, as the $Z_{\mathrm{et}}$ value is decreased, provides some hope to partially correct CloudSat retrievals. Knowing cloud-base heights may improve CloudSat retrievals of LWP. Because robust cloud-base measurements are not readily available from space, accounting for these heights from climatological mean data may be an option for improvements of spaceborne radar estimates of cloud content. Given the aforementioned limitations in marine stratiform cloud sensing from space, one can suggest that CloudSat measurements could be more efficiently used for inferring drizzle parameters. More sensitive satelliteborne radars designed for later space missions (e.g., Bezy et al. 2002) can be expected to provide better information than CloudSat for clouds in which the effects of drizzle are small.

Overall, the reflectivity thresholding approach can be 


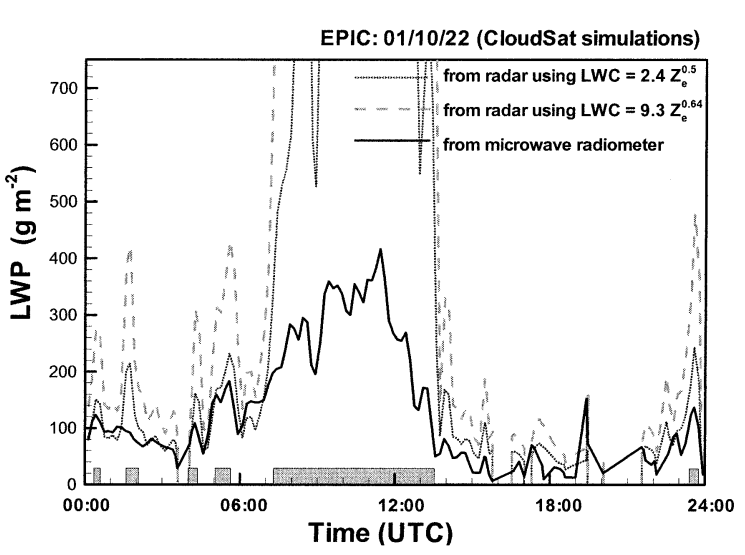

a)

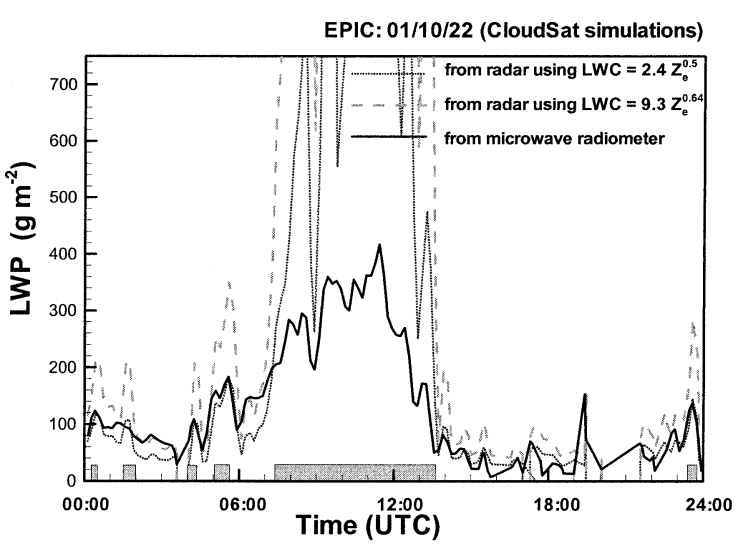

FIG. 9. Same as Fig. 7, but for 22 Oct 2001. Gray bars on the time axis indicate periods when radar profiles contained $Z_{e}>-15 \mathrm{dBZ}$.

considered as a viable option for selecting radar profiles for which estimates of cloud content from reflectivityonly measurements can be performed with a degree of uncertainty that depends on the thresholding level. Though this approach does not provide a rigorous means of separating drizzle and drizzle-free profiles, it can be used when the specified uncertainties of retrievals can be tolerated. When additional information (e.g., cloudbase height) is available, reflectivity-based retrievals can be improved and the thresholding procedure can be used in a more efficient way (e.g., thresholding in the lower half of the cloud) for identifying situations without appreciable presence of drizzle. The performance of the thresholding approach depends on the resolution and sensitivity of measurements. It provides better results for more sensitive and better resolved measurements from ground radars.

Acknowledgments. This research was funded by the CloudSat and EPIC projects and, in part, by the U.S. Department of Energy Atmospheric Radiation Measurement (ARM) Program.
REFERENCES

Atlas, D., 1954: The estimation of cloud parameters by radar. $J$. Meteor., 11, 309-317.

Austin, R. T., and G. L. Stephens, 2001: Retrieval of stratus cloud microphysical parameters using millimeter-wave radar and visible optical depth in preparation for CloudSat. 1. Algorithm formulation. J. Geophys. Res., 106, 28 233-28 242.

Bezy, J. L., K. Kondo, H. Kumagai, W. Leibrandt, C. C. Lin, J. P. V. Poiares Baptista, P. L. Silvestrin, and M. Suzuki, 2002: The EarthCARE mission. Proc. Second Int. Workshop on SpaceBorne Cloud Profiling Radar, Tokyo, Japan, Communications Research Laboratory (CRL), 23-32.

Bretherton, C. S., T. Uttal, C. W. Fairall, S. Yuter, R. Weller, D. Baumgardner, K. Comstock, and R. Wood, 2004: The EPIC 2001 stratocumulus study. Bull. Amer. Meteor. Soc., in press.

Clothiaux, E. E., M. A. Miller, B. A. Albrecht, T. P. Ackerman, J. Verlinde, D. M. Babb, R. M. Peters, and W. J. Sytrett, 1995: An evaluation of a $94-\mathrm{GHz}$ radar for remote sensing of cloud properties. J. Atmos. Oceanic Technol., 12, 201-229.

Dong, X., and G. G. Mace, 2003: Profiles of low-level stratus cloud microphysics deduced from ground-based measurements. J. Atmos. Oceanic Technol., 20, 42-53.

Fox, N. I., and A. J. Illingworth, 1997: The retrieval of stratocumulus cloud properties by ground-based cloud radar. J. Appl. Meteor. 36, 485-492.

Frisch, A. S., C. W. Fairall, and J. B. Snyder, 1995: Measurement of stratus cloud and drizzle parameters in ASTEX with a Ka-band Doppler radar and a microwave radiometer. J. Atmos. Sci., 52, 2788-2799.

—-, M. Shupe, I. Djalalova, G. Feingold, and M. Poellot, 2002: The retrieval of stratus cloud droplet equivalent radius with cloud radars. J. Atmos. Oceanic Technol., 19, 835-842.

Greenwald, T. J., G. L. Stephens, S. A. Cristopher, and T. H. Vonder Haar, 1995: Observations of the global characteristics and regional radiative effects of marine cloud liquid water. J. Climate, 8, 2928-2945.

Han, Q., W. B. Rossow, and A. A. Lacis, 1994: Near global survey of effective droplet radii in liquid water clouds using ISCCP data. J. Climate, 7, 465-497.

Lin, B., and W. B. Rossow, 1994: Observations of cloud liquid water path over oceans: Optical and microwave remote sensing methods. J. Geophys. Res., 99, 20 907-20 927.

Loehnert, U., S. Crewell, A. Macke, and C. Simmer, 2001: Profiling cloud liquid water by combining active and passive microwave measurements with cloud model statistics. J. Atmos. Oceanic Technol., 18, 1354-1366.

Mace, G. G., and K. Sassen, 2000: A constrained algorithm for retrieval of stratocumulus cloud properties using solar radiation, microwave radiometer, and millimeter cloud radar data. J. Geophys. Res., 105, 29 099-29 108.

Matrosov, S. Y., 2000: Estimation of stratus cloud microphysical parameters based on measurements of radar reflectivity profiles. Preprints, Fifth Int. Symp. on Tropospheric Profiling, Adelaide, Australia, ATRAD, 209-211.

Matveev, L. T., 1976: Physics of the Atmosphere. Gidrometeorizdat, $640 \mathrm{pp}$.

Miles, N. L., J. Verlinde, and E. E. Clothiaux, 2000: Cloud droplet size distributions in low-level stratiform clouds. J. Atmos. Sci., 57, 295-311.

Minnis, P., D. P. Garber, D. F. Young, R. F. Arduni, and Y. Takano, 1998: Parameterization of reflectance and effective remittance for satellite remote sensing of cloud properties. J. Atmos. Sci., $\mathbf{5 5}, 3313-3339$.

Rozenberg, V. I., 1972: Scattering and Extinction of Electromagnetic Radiation by Atmospheric Particles. Gidrometeoizdat, $348 \mathrm{pp}$.

Sassen, K., and L. Liao, 1996: Estimation of cloud content by Wband radar. J. Appl. Meteor., 35, 932-938.

-, G. G. Mace, Z. Wang, M. R. Poelot, S. M. Sekelsky, and R. E. McIntosh, 1999: Continental stratus clouds: A case study 
using coordinated remote sensing and aircraft measurements. $J$. Atmos. Sci., 56, 2345-2358.

Sauvegeout, H., and J. Omar, 1987: Radar reflectivity of cumulus clouds. J. Atmos. Oceanic Technol., 4, 264-272.

Stepanenko, V. D., G. G. Schukin, L. P. Bobylev, and S. Y. Matrosov, 1987: Microwave Radiometry in Meteorology. Gidrometeoizdat, 284 pp.

Stephens, G. L., and the CloudSat Science Team, 2002: The CloudSat Mission and the A-train. A new dimension of space-based observations of clouds and precipitation. Bull. Amer. Meteor. Soc., 83, 1771-1790.

Uttal, T., and R. A. Kropfli, 2001: The effect of radar pulse length on cloud reflectivity statistics. J. Atmos. Oceanic Technol., 18, 947-961.
Wang, J., and B. Geerts, 2003: Identifying drizzle within marine stratus with W-band radar reflectivity. Atmos. Res., 69, 1-27.

Westwater, E. R., Y. Han, M. D. Shupe, and S. Y. Matrosov, 2001: Analysis of integrated cloud liquid and precipitable water vapor retrievals from microwave radiometers during the Surface Heat Budget of the Arctic Ocean project. J. Geophys. Res., 106, 32 019-32030.

Young, D. F., P. Minnis, W. L. Smith Jr., and D. P. Garber, 1997: A four channel method for deriving cloud radiative properties from meteorological satellite data. IRS '96: Current Problems in Atmospheric Radiation, W. L. Smith and K. Stamnes, Eds., Deepak, 612-615.

Zuidema, P., and D. L. Hartmann, 1995: Satellite determination of cloud microphysical properties. J. Climate, 8, 1638-1657. 